\title{
Comprehensive Evaluation Method of High-Rise Building Green Construction Based on Cloud Model
}

\author{
Xu Tang, Yijun Chen \\ School of Management, Sichuan University of Science \& Engineering, Zigong, China \\ Email: 183321448@qq.com
}

How to cite this paper: Tang, X., \& Chen, Y. J. (2021). Comprehensive Evaluation Method of High-Rise Building Green Construction Based on Cloud Model. Open Journal of Business and Management, 9, 2719-2734. https://doi.org/10.4236/ojbm.2021.96150

Received: September 6, 2021

Accepted: October 30, 2021

Published: November 2, 2021

Copyright $\odot 2021$ by author(s) and Scientific Research Publishing Inc. This work is licensed under the Creative Commons Attribution International License (CC BY 4.0).

http://creativecommons.org/licenses/by/4.0/

\begin{abstract}
With resource conservation, environmental protection and people's health being valued by the whole society, high-rise building green construction has become an irresistible trend. For accurate evaluation of high-rise building green construction assessment level, considering the fuzziness and randomness, green construction assessment based on the perspective of construction general contracting unit, through literature research and the influence factors of in-situ investigation to determine the influence of green construction, using the PSR theory constructing evaluation index system of green construction, adopt AHP, entropy weight method to calculate the combination weight of index system. Finally, the transformation between qualitative and quantitative was realized by using cloud model, and the comprehensive evaluation level was established by drawing comprehensive cloud map and calculating membership degree. Combined with a municipal representative project, the green construction evaluation simulation calculation, the calculation results show that the project green construction evaluation grade is good, feedback of the results to the general contractor has been generally recognized.
\end{abstract}

\section{Keywords}

High-Rise Building, Green Construction, AHP-Entropy Weight Method, Cloud Model

\section{Introduction}

In recent years, as the concept of sustainable development continues to gain popularity, people's awareness of environmental protection is enhanced, and the country actively advocates green, low-carbon and environmental protection policies, green construction has become an important direction for the future de- 
velopment of the construction industry. At the same time, the rapid growth of urban population makes urban high-rise buildings develop rapidly, the building scale is getting bigger and bigger, and the height is also getting higher and higher. With its large floor area ratio, high-rise buildings gradually become an important part of the city. As a pillar industry of the national economy, the construction industry plays an extremely important role in social development, but at the same time, the construction industry is also one of the industries that consume the most natural resources and energy, destroy the most land and produce the most air pollution, and has a huge demand for many non-renewable resources. According to the Annual Development Research Report on Building Energy Efficiency in China, the energy consumption of China's civil buildings in 2018 was 520 million TCE, accounting for about $11 \%$ of the national energy consumption, and the total carbon emission related to the construction of civil buildings was about 1.8 billion ton $\mathrm{CO}_{2}$. Therefore, it is necessary to change the thinking of building, adopt the concept of "green construction" in line with the current, so that the resources in the construction process of high-rise buildings can be fully utilized, and unnecessary resources and energy waste can be reduced to realize the construction of ecological civilization and promote the sustainable development of society.

\section{Literature Review}

At present, around the promotion and standardization of green construction, a large number of scholars have studied the evaluation index system and evaluation method of green construction, and achieved rich results. Li Yingpan et al. (2018a) constructed the green construction evaluation index system through the literature research method, and used BP artificial neural network to evaluate the established index system. Chen Xiaohong (2006) constructed the green construction evaluation index system and established the evaluation model from the five dimensions of management, construction personnel service level, environment, resources and energy. Wang Ailing (2014) combined with the characteristics of green construction to build the green construction evaluation index system, in order to improve vague similarity summary method to establish the green construction evaluation model of building engineering. Yang Tao et al. (2008) established the green construction index evaluation system according to the green building evaluation standards and criteria and the consultation of engineering experts, and used the grey clustering method to build the green construction evaluation model. In addition, Wang Qiankun et al. (2020), Gao Lin et al. (2017), Xie Shijun (2018), Chai Naijie et al. (2017), Shi Zhenwu and Hua Shuxin (2019) on prefabricated buildings, underground engineering, water conservancy and hydropower engineering, railway engineering and season frozen area highway construction as the research object, according to the construction characteristics of the project using different methods of its green construction 
index system and evaluation model are studied. However, for different types of construction projects, there seems to be no completely unified and effective evaluation method system for green construction of construction enterprises. In addition, current studies mainly tend to evaluate green construction from the perspective of construction units and social environmental protection, while few studies evaluate green construction from the perspective of general contractor, and the main implementer and responsible person of green construction is the general contractor. Therefore, based on the PSR theoretical model, this paper studies the green construction of high-rise buildings from the perspective of general contractor, which enrich the current perspective of green construction research. At the same time, it makes general contractor fully understand and understand green construction, turns passive into active acceptance of green construction, and promotes the further development and promotion of green construction in the construction industry.

\section{Green Construction Index System of High-Rise Building Based on PSR Theory}

\subsection{PSR Theoretical Conceptual Model}

PSR (Pressure-state-response) theoretical model was first proposed by Canadian statisticians David J. Rapport and Tony Friend. Later, the Organization for Economic Cooperation and Development (OECD) and the United Nations Environment Programme (UNEP) jointly developed a framework for studying environmental issues. PSR model includes three parts: pressure, state and response. Where, pressure refers to the pressure of population and social and economic development on the environment; state is used to describe the environmental state and environmental changes within a specific time; response refers to the measures taken by the government, society and individuals to mitigate, prevent, recover and prevent the negative impact of human activities on the environment (Guo et al., 2021; Xue \& Zhao, 2021; Li \& Liu, 2021). The three parts interact with each other, and the dynamic relationship is shown in Figure 1 below

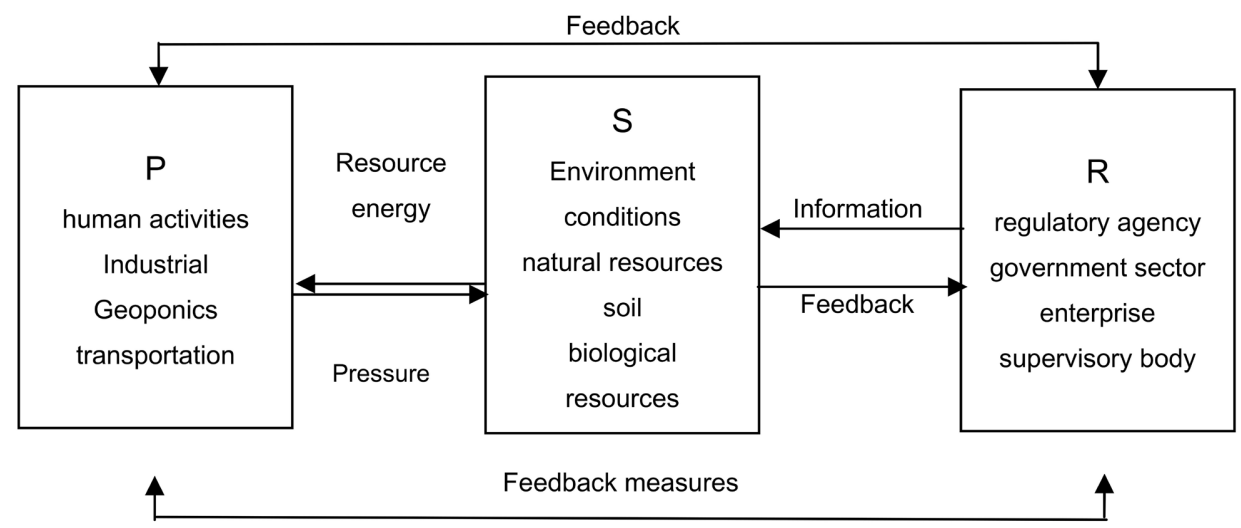

Figure 1. PSR theoretical conceptual model. Note: Figure 1 is from the author's summary of literature. 


\subsection{Green Construction Index System of High-Rise Building}

Based on the idea of PSR framework model and combined with the construction characteristics of high-rise buildings, the evaluation index system of green construction of high-rise buildings is constructed from three aspects of "pressurestate-response". Through literature research, expert consultation and other methods, combined with the principles of simplicity, systematization, operability, combination of qualitative and quantitative of green construction index system, the green construction index system of high-rise buildings was established, including 12 first-level indexes and 36 second-level indexes. Among them, the index content of pressure type includes: human resources saving and occupational health and safety, the organization and management of field personnel, the satisfaction of surrounding residents, safety and health management; State type indicators include: land resources conservation and utilization, building materials conservation and utilization, energy conservation and utilization, water resources conservation and utilization; Response status indicators include: surrounding resource protection, environmental protection, construction waste control, innovative technologies and measures. The specific indicator types and influencing factors are shown in Table 1.

Table 1. Index system of influencing factors of green construction.

\begin{tabular}{|c|c|c|c|c|c|c|}
\hline \multicolumn{2}{|c|}{ Type Level indicators } & \multirow{2}{*}{$\begin{array}{l}\text { The secondary indicators } \\
\text { Saving of human resources } A_{11}\end{array}$} & \multirow{2}{*}{$\begin{array}{l}\text { Nature } \\
\text { ration }\end{array}$} & \multirow{2}{*}{$\begin{array}{l}\text { AHP } \\
0.0140\end{array}$} & \multirow{2}{*}{$\begin{array}{l}\text { entropy } \\
\text { weight method } \\
0.1011\end{array}$} & \multirow{2}{*}{$\begin{array}{l}\text { combination } \\
\text { weight }\end{array}$} \\
\hline \multirow{11}{*}{$\mathrm{P}$} & $\begin{array}{l}\text { Human resource } \\
\text { conservation and }\end{array}$ & & & & & \\
\hline & $\begin{array}{l}\text { occupational health and } \\
\text { safety }(0.0808)\end{array}$ & Occupational health and safety $A_{12}$ & qualitative & 0.0444 & 0.0000 & 0.0222 \\
\hline & \multirow{3}{*}{$\begin{array}{l}\text { Personnel organization } \\
\text { management }(0.0943)\end{array}$} & $\begin{array}{l}\text { Organize and manage green construction } \\
\text { personnel } A_{21}\end{array}$ & qualitative & 0.0377 & 0.0406 & 0.0391 \\
\hline & & $\begin{array}{l}\text { Coordination of professional } \\
\text { subcontracting } A_{22}\end{array}$ & qualitative & 0.0226 & 0.0259 & 0.0243 \\
\hline & & Personnel change in project department $A_{2}$ & qualitative & 0.0132 & 0.0485 & 0.0309 \\
\hline & \multirow{2}{*}{$\begin{array}{l}\text { Satisfaction of } \\
\text { surrounding residents } \\
(0.0719)\end{array}$} & Noise control $A_{31}$ & qualitative & 0.0328 & 0.0525 & 0.0427 \\
\hline & & Light pollution control $A_{32}$ & qualitative & 0.0149 & 0.0436 & 0.0293 \\
\hline & \multirow{4}{*}{$\begin{array}{l}\text { Safety and health } \\
\text { management }(0.1478)\end{array}$} & Safety precautions $A_{41}$ & qualitative & 0.0656 & 0.0149 & 0.0402 \\
\hline & & $\begin{array}{l}\text { Health and epidemic prevention } \\
\text { management } A_{42}\end{array}$ & qualitative & 0.0338 & 0.0485 & 0.0411 \\
\hline & & Fire control facilities $A_{43}$ & qualitative & 0.0212 & 0.0237 & 0.0224 \\
\hline & & Emergency response plan $A_{44}$ & qualitative & 0.0487 & 0.0393 & 0.0440 \\
\hline \multirow{3}{*}{$S$} & \multirow{3}{*}{$\begin{array}{l}\text { Land resources } \\
\text { conservation and } \\
\text { utilization }(0.0568)\end{array}$} & Vertical conveyance $B_{11}$ & qualitative & 0.0250 & 0.0059 & 0.0154 \\
\hline & & The construction of road $B_{12}$ & qualitative & 0.0146 & 0.0102 & 0.0124 \\
\hline & & $\begin{array}{l}\text { Effective utilization of temporary facilities } \\
B_{13}\end{array}$ & ration & 0.0235 & 0.0344 & 0.0290 \\
\hline
\end{tabular}




\begin{tabular}{|c|c|c|c|c|c|c|}
\hline & \multirow{4}{*}{$\begin{array}{l}\text { Saving and utilization of } \\
\text { building materials } \\
(0.0640)\end{array}$} & Local rate $B_{21}$ & ration & 0.0169 & 0.0007 & 0.0088 \\
\hline & & Loss rate of major building materials $B_{22}$ & ration & 0.0190 & 0.0229 & 0.0209 \\
\hline & & Ratio of waste to building materials $B_{23}$ & ration & 0.0253 & 0.0051 & 0.0152 \\
\hline & & Utilization rate of green materials $B_{24}$ & ration & 0.0379 & 0.0003 & 0.0191 \\
\hline & \multirow{3}{*}{$\begin{array}{l}\text { Energy conservation and } \\
\text { utilization }(0.0754)\end{array}$} & Proportion of energy saving equipment $B_{31}$ & ration & 0.0372 & 0.0004 & 0.0188 \\
\hline & & Power savings $B_{32}$ & ration & 0.0196 & 0.0546 & 0.0371 \\
\hline & & Green energy utilization measures $B_{33}$ & qualitative & 0.0389 & 0.0001 & 0.0195 \\
\hline & \multirow{3}{*}{$\begin{array}{l}\text { Water resources } \\
\text { conservation and } \\
\text { utilization }(0.0455)\end{array}$} & Non-traditional water utilization $B_{41}$ & ration & 0.0138 & 0.0154 & 0.0146 \\
\hline & & To save water $B_{42}$ & ration & 0.0284 & 0.0057 & 0.0170 \\
\hline & & $\begin{array}{l}\text { Utilization rate of water-saving equipment } \\
B_{43}\end{array}$ & ration & 0.0277 & 0.0000 & 0.0138 \\
\hline \multirow{12}{*}{$\mathrm{R}$} & \multirow{4}{*}{$\begin{array}{l}\text { Protection of } \\
\text { surrounding resources } \\
(0.0742)\end{array}$} & Soil conservation $C_{11}$ & qualitative & 0.0082 & 0.0187 & 0.0134 \\
\hline & & $\begin{array}{l}\text { Measures to prevent settlement around } \\
\text { foundation pit } C_{12}\end{array}$ & qualitative & 0.0184 & 0.0116 & 0.0150 \\
\hline & & Protection of groundwater resources $C_{13}$ & qualitative & 0.0200 & 0.0182 & 0.0191 \\
\hline & & Pipeline protection $C_{14}$ & qualitative & 0.0217 & 0.0317 & 0.0267 \\
\hline & \multirow{4}{*}{$\begin{array}{l}\text { Environmental } \\
\text { protection }(0.1405)\end{array}$} & Dust management $C_{21}$ & qualitative & 0.0160 & 0.0639 & 0.0400 \\
\hline & & On-site enclosure management $C_{22}$ & qualitative & 0.0132 & 0.0227 & 0.0179 \\
\hline & & Toxic substance control $C_{23}$ & qualitative & 0.0839 & 0.0213 & 0.0526 \\
\hline & & Wastewater treatment $C_{24}$ & qualitative & 0.0438 & 0.0253 & 0.0345 \\
\hline & \multirow{2}{*}{$\begin{array}{l}\text { Construction waste } \\
\text { management }(0.0687)\end{array}$} & Resource reduction $C_{31}$ & qualitative & 0.0444 & 0.0297 & 0.0371 \\
\hline & & Garbage disposal $C_{32}$ & qualitative & 0.0317 & 0.0316 & 0.0317 \\
\hline & \multirow{2}{*}{$\begin{array}{l}\text { Innovative technology } \\
\text { and measures }(0.0755)\end{array}$} & "Four new" technology application $C_{41}$ & qualitative & 0.0090 & 0.0050 & 0.007 \\
\hline & & Building assembly rate $C_{42}$ & ration & 0.013 & 0.1241 & 0.0685 \\
\hline
\end{tabular}

Note: The index system in Table 1 comes from the author's reference to literature, and the index weight comes from the author's sorting and calculation of the collected data.

\subsection{Establish Evaluation Criteria}

In order to ensure the accuracy and rationality of the standard value of the evaluation index, based on the reference of domestic research results, According to the actual situation, national standards such as Green Building Evaluation Standard, Green Construction Evaluation Standard of Building Engineering, local standards such as Construction Site Safety protection, Site sanitation and Fire Protection Standard and the standard values of green construction technology demonstration project are selected as the reference standards of this study. Based on the comprehensive grading of evaluation indexes at home and abroad, in order to better distinguish the differentiation of evaluation results of green construction, this paper divides the evaluation indexes of green construction into five grades. The qualified grade is divided into four grades, which are excellent, 
good, medium and qualified grade, and one unqualified grade is added. As for the grading standards of evaluation indexes, the lowest and highest standards of each evaluation index are determined on the basis of consulting relevant standards and specifications, and on this basis, the grading standard interval of each evaluation index is determined by linear interpolation method ( $\mathrm{Li}, 2012)$. The specific qualitative and quantitative criteria are shown in Table 2 and Table 3. Due to the word limit, only part of the criteria is listed here, and the other criteria are similar.

\section{Establish the Weight of the Index System}

The establishment of the weight of the green construction evaluation index system of high-rise buildings will directly affect the accuracy of the green construction evaluation. In order to determine the weight of the green construction index system more accurately and reasonably, In this paper, the Analytic Hierarchy process (AHP) is combined with entropy weight method to establish the weight of green construction indicators (Gao, 2009).

The analytic hierarchy process (AHP) constructs a comparison matrix by sending questionnaires to civil engineering teachers and professors. A total of 12 questionnaires were sent out and 12 were recovered, accounting for 100\%. Among them, 8 were valid, accounting for $66.7 \%$. The actual engineering data used by entropy weight method came from 9 green construction demonstration projects that were selected as provincial or municipal level. Due to space limitation here, the specific data and calculation process of the analytic hierarchy Process and the entropy weight method are not presented here. The final weights obtained by the entropy weight method and the analytic hierarchy process and the final combined weights are shown in Table 1. It can be seen from the table that safety and health management and environmental protection account for a

Table 2. Classification standards of quantitative indicators (\%).

\begin{tabular}{cccccc}
\hline level & unqualified & qualified & medium & good & excellence \\
\hline Non-traditional water utilization & $<5 \%$ & {$[5 \%, 10 \%)$} & {$[10 \%, 15 \%)$} & {$[15 \%, 20)$} & $\geq 20 \%$ \\
To save water & $<2 \%$ & {$[2 \%, 4.6 \%)$} & {$[4.6 \%, 7.2 \%)$} & {$[7.2 \%, 10 \%)$} & $\geq 10 \%$ \\
Utilization rate of green building materials & $<30 \%$ & {$[30 \%, 43.3 \%)$} & {$[43.3 \%, 56.6 \%)$} & {$[56.6 \%, 70 \%)$} & $\geq 70 \%$ \\
\hline
\end{tabular}

Note: Table 2 is from the author's summary of national standards and specifications and literature.

Table 3. Classification standards of qualitative Indicators (100").

\begin{tabular}{cccccc}
\hline level & unqualified & qualified & medium & good & excellence \\
\hline Noise control & $<60$ & {$[60,70)$} & {$[70,80)$} & {$[80,90)$} & $\geq 90$ \\
Light pollution control & $<60$ & {$[60,70)$} & {$[70,80)$} & {$[80,90)$} & $\geq 90$ \\
Dust management & $<60$ & {$[60,70)$} & {$[70,80)$} & {$[80,90)$} & $\geq 90$ \\
\hline
\end{tabular}

Note: Table 3 is from the author's summary of national standards and specifications and literature. 
large proportion among all the weight factors of first-level indicators, which are 0.1478 and 0.1405 respectively. Instructions from contractor's perspective, the traditional concept of "four a environmental protection" in the environmental protection in the present moment is still very important in the new concept of green construction, to a certain extent also complied with the 19th session of five proposed to promote the green development, promote the green development of the harmonious coexistence between man and nature philosophy, but also increases the safety and health of this new green construction influence factors, It can be seen that with the economic development of The Times, the construction industry pays more attention to the health and safety of construction workers and humanistic care while protecting the environment, which also makes the connotation of green construction development concept richer.

\subsection{Analytic Hierarchy Process}

Analytic hierarchy Process by the University of Pittsburgh professor Sati proposed a simulation of human analysis, judgment and decision-making system analysis method. This method is widely used in hierarchical weight decision analysis and multi-index evaluation model. Its specific idea is: according to the characteristics and nature of the problem to determine the overall goal; Then, the problem is hierarchical and an orderly hierarchical system is established. Compare and judge the factors in pairs, and finally determine the relative weight of the factors relative to the overall goal through comprehensive calculation.

The basic steps of chromatography are as follows:

1) Construct the judgment matrix according to the determined general objective

$A=\left(a_{i j}\right)_{n \times n}$ (Judgment of relative importance of $i$ and $j$ factors), $(i=1,2,3, \cdots, n, \quad j=1,2,3, \cdots, n)$

2) The judgment matrix is normalized by column;

$$
b_{i j}=a_{i j} / \sum_{i=1}^{n} a_{i j}
$$

3) Weight calculation

$$
\begin{aligned}
& \text { Weight } U=\left(u_{1}, u_{2}, u_{3}, \cdots, u_{n}\right)^{\mathrm{T}} \text {; } \\
& \qquad u_{i}=\sum_{j=1}^{n} b_{i j} / n
\end{aligned}
$$

4) Consistency test

1) The maximum eigenvalue of the original judgment matrix, $\lambda$, is obtained according to the formula $A U=\lambda U$;

$$
\lambda=\frac{1}{n} \sum_{i=1}^{n} \frac{[A U]_{i}}{u i} ;
$$

2) Define consistency indicators: $C I=\frac{\lambda-n}{n-1}$; CI represents the degree of deviation from consistency of judgment matrix, and the closer $\mathrm{CI}$ is to 0 , the better; 
3) Adopt consistency ratio CR as the indicator of consistency test of judgment matrix, $\mathrm{CR}=\frac{\mathrm{CI}}{\mathrm{RI}}$, $\mathrm{RI}$ represents the random consistency indicator, which is generally obtained by looking up a table. The random consistency indicator table is shown in Table 4.

It is generally accepted that the conformance test is passed when $\mathrm{CR}<0.1$.

\subsection{Entropy Weight Method}

Entropy, in physics, measures disorder in a thermodynamic system. In 1948, Shannon put forward the concept of information entropy, that is, quantitatively describe how many pieces of information a piece of information contains, and give the information entropy formula by using the statistical characteristics of Markov process $H=-K \sum_{i=1}^{m} p_{i} \ln p_{i}$. In this paper, entropy weight method is used to confirm the weight of green construction evaluation index system, mainly to reduce the subjective randomness of determining the weight of index system. The main idea of entropy weight method is that the greater the difference of indicator values of various factors in green construction, the greater the amount of information provided by the indicator, and the greater the weight given by the indicator ( $\mathrm{Hu}, 2012)$.

The basic analysis of entropy weight method is as follows:

1) Calculate the original matrix $A=\left(a_{i j}\right)_{m \times n}$ (where $a_{i j}$ represents the $i$ th actual score of index $j, i=1,2,3, \cdots, M, \quad j=1,2,3, \cdots, N)$ Probability of each value under each index $p_{i j}=a_{i j} / \sum_{i=1}^{m} a_{i j}$;

2) According to the formula $H_{j}=-\frac{1}{\ln m} \sum_{i=1}^{m} p_{i j} \ln p_{i j} \quad$ Calculate the information entropy $H_{j}$ of each index;

3) According to the formula $v_{j}=\frac{1-H_{j}}{\sum_{j=1}^{n}\left(1-H_{j}\right)}$ The weight $v_{j}$ of each index can be obtained.

\subsection{Establish Comprehensive Weight of Indicators}

The comprehensive weight of indicators $w_{1}, w_{2}, w_{3}, \cdots, w_{n}$, and the formula is $w_{i}=\left(u_{i}+v_{i}\right) / 2$;

$u_{i}$ is the subjective weight obtained by analytic hierarchy process, and $v_{i}$ is the objective weight obtained by entropy weight method.

Table 4. Random consistency indicator.

\begin{tabular}{|c|c|c|c|c|c|c|c|c|c|c|c|c|c|c|}
\hline$n$ & 1 & 2 & 3 & 4 & 5 & 6 & 7 & 8 & 9 & 10 & 11 & 12 & 13 & 14 \\
\hline RI & 0 & 0 & 0.52 & 0.89 & 1.12 & 1.26 & 1.36 & 1.41 & 1.46 & 1.49 & 1.52 & 1.54 & 1.56 & 1.58 \\
\hline
\end{tabular}

Note: The RI in Table 4 was calculated by MATLAB software. 


\section{Cloud Model}

In 1995, Professor Li Deyi, an academician of the Chinese Academy of Engineering, proposed an uncertain reasoning theory-cloud model. As an uncertain transformation model of qualitative concept and quantitative description, this model fully reveals the fuzziness and randomness of evaluation objects, and is an effective tool to achieve qualitative and quantitative transformation. The cloud model uses the expected Ex, entropy En, and superentropy He to represent a qualitative concept. Expectation Ex is the point that best represents qualitative concepts in the domain space. Entropy En is a measure of randomness of qualitative concepts, which reflects the value range of cloud droplets that can be accepted by concepts in the domain space. Hyperentropy $\mathrm{He}$ is a measure of entropy uncertainty, namely the entropy of entropy, which is determined by the randomness and fuzziness of entropy.

The numerical eigenvalues (Ex, En, $\mathrm{He}$ ) reflecting the qualitative concept can be calculated as follows:

Calculate its mean value according to the obtained data sample $x_{i}$,

$$
\bar{X}=\frac{\sum_{i=1}^{n} x_{i}}{n}
$$

First order sample center moment

$$
\frac{1}{n} \sum_{i=1}^{n}\left|x_{i}-\bar{X}\right|
$$

Sample variance

$$
\begin{gathered}
S^{2}=\frac{1}{n-1} \sum_{i=1}^{n}\left(x_{i}-\bar{X}\right)^{2} \\
\mathrm{Ex}=\bar{X} \\
\mathrm{En}=\sqrt{\frac{\pi}{2}} \times \frac{1}{n} \sum_{i=1}^{n}\left|x_{i}-\bar{X}\right| \\
\mathrm{He}=\sqrt{\left|S^{2}-\mathrm{En}^{2}\right|}
\end{gathered}
$$

\subsection{Establishing the Standard Cloud}

In this study, the field of evaluation index value is set as $[0,100]$, and it is divided into 5 sub-intervals according to the standard of evaluation grade, among which the $i$ th sub-interval is $\left[x_{\min }^{i}, x_{\max }^{i}\right]$, The calculation formula of standard cloud digital features (Exi, Eni, Hei) of the $i$-th subregion is as follows:

$$
\begin{gathered}
\text { Exi }=\left(x_{\text {min }}^{i}+x_{\text {max }}^{i}\right) / 2 \\
\text { Eni }=\left(x_{\text {max }}^{i}-x_{\text {min }}^{i}\right) / 2 \sqrt{2 \ln 2} \\
\text { Hei }=k .
\end{gathered}
$$

$k$ is a constant and can be adjusted according to the ambiguity of the variable 
(Li Yingpan et al., 2018b).

According to formula 4.1.1 and 4.1.2, the cloud digital characteristic values are shown in Table 5.

\subsection{Establishment of Comprehensive Evaluation Cloud}

Combined with the weight of the index system obtained above, the calculation formula of the digital characteristic value ( $\mathrm{Ex}, \mathrm{En}, \mathrm{He}$ ) of the comprehensive evaluation cloud is as follows:

$$
\begin{aligned}
\mathrm{Ex} & =\sum_{i=1}^{n} \mathrm{Ex}_{i} w_{i} \\
\mathrm{En} & =\sqrt{\sum_{i=1}^{n} \mathrm{En}_{i}^{2} w_{i}} \\
\mathrm{He} & =\sum_{i=1}^{n} \mathrm{He}_{i} w_{i}
\end{aligned}
$$

\subsection{Computing Cloud Similarity and Performance Assessment Level}

By the similarity calculation formula, the $\psi$ of the digital characteristic values $(\mathrm{Ex}, \mathrm{En}, \mathrm{He})$ of the comprehensive evaluation cloud and the digital characteristics (Exi, Eni, Hei) of the evaluation standard cloud were calculated, and the evaluation grade of green construction was determined. The larger the similarity is, the closer the evaluation level of green construction is to the standard level, and the $\psi$ with the largest similarity is taken as the evaluation level of green construction. The calculation method of similarity is as follows:

1) Generate a random positive number $\operatorname{Exk}=R_{N}(E n, H e)$ with En as expected value and $\mathrm{He}^{2}$ as variance;

2) Generate a random positive number $X k=R_{N}(E x, E x k)$ with Ex as expected value and $\mathrm{Exk}^{2}$ as variance;

3) Bring $\mathrm{Xk}$ into the $i$ th evaluation standard cloud to calculate $\delta_{k}$, and the formula is as follows:

$$
\delta_{k}=\exp \left[-\frac{(\mathrm{Xk}-\mathrm{Exi})^{2}}{2 \mathrm{Eni}^{2}}\right]
$$

Table 5. Evaluation standard cloud interval division.

\begin{tabular}{cccc}
\hline standard cloud & Green construction evaluation standard & Interval differentiate & Digital characteristics (Ex, En, He) \\
\hline 1 & unqualified & {$[0,60]$} & $(30,25.4797,0.5)$ \\
2 & qualified & {$[60,70]$} & $(65,4.2466,0.5)$ \\
3 & medium & {$[70,80]$} & $(75,4.2466,0.5)$ \\
4 & good & {$[80,90]$} & $(85,4.2466,0.5)$ \\
5 & excellence & {$[90,100]$} & $(95,4.2466,0.5)$ \\
\hline
\end{tabular}

Note: The data in Table 5 are calculated by the author through formula 4.1.1 and Formula 4.1.2. 
4) Repeat steps (1-3) until $n \delta_{k}$ is generated, generally $n=3000$, calculate the similarity $\psi_{i} ;$

$$
\psi_{i}=\frac{1}{n} \sum_{i=1}^{n} \delta_{k}
$$

\section{Empirical Analysis}

\subsection{Project Overview}

The first-phase housing construction project located in a city covers an area of $233 \mathrm{mu}$ with a plot ratio of 1.8. The total construction area is about 140,000 square meters and there are 820 households. The phase I project consists of five residential buildings, four of which are single buildings and one connected building divided into two units, with a minimum of 25 storeys and a maximum of 29 storeys.

In the construction of the residential project in construction of high-grade village construction target, combined with its along the Yangtze river is located in the Sanjiang confluence, thus planning fully draw inspiration from the Chinese traditional landscape brushwork, respecting nature, mountain, water, building harmonious coexistence between man and, in the design gimmick, the courtyard layout, the garden to the air, Realize the city of sky with spreading landscape. Due to its unique geographical location and advanced design concept, the general contractor was required to organize the construction according to the Evaluation Standard for Green Construction of Building Engineering at the time of bidding, take a series of measures for environmental protection, control the water pollution and air pollution around, and implement green construction. To achieve the "building engineering green construction evaluation standard" GBT50640-2010 provisions of the qualified standard. In the on-site interview, the first interview to the overall contractor's project manager, in order to have preliminary knowledge of the whole construction project, and then under the introduction of the project manager for each department personnel interview, interview object, at least, is engaged in the project management more than 3 years with rich experience in project management and staff to fully understand the current project, After the interview, the interviewers were invited to score the green construction questionnaire on site. A total of 15 grading questionnaires were obtained. One of the questionnaires was rated as follows: $A_{11}=$ $2.72 \%, A_{12}=90, A_{21}=91, A_{22}=82, A_{23}=73, A_{31}=90, A_{32}=91, A_{41}=90, A_{42}=$ 92, $A_{43}=85, A_{44}=90, B_{11}=92, B_{12}=70, B_{13}=98.2 \%, B_{21}=70 \%, B_{22}=14.3 \%, B_{23}$ $=60 \%, B_{24}=95 \%, B_{31}=75 \%, B_{32}=0.55 \%, B_{33}=60, B_{41}=22 \%, B_{42}=11.6 \%, B_{43}=$ $50 \%, C_{11}=90, C_{12}=91, C_{13}=95, C_{14}=90, C_{21}=92, C_{22}=90, C_{23}=95, C_{24}=92$, $C_{31}=82, C_{32}=70, C_{41}=82, C_{42}=40$.

\subsection{Calculate Each Indicator Cloud and Comprehensive Cloud}

According to formula (4.1)-(4.6) above, indicator clouds and comprehensive clouds are calculated as shown in Table $6(i=1,2,3,4, \cdots, 15)$ : 
Table 6. Digital features of clouds.

\begin{tabular}{cccccccc}
\hline Index & Exi, Eni, Hei & Index & Exi, Eni, Hei & Index & Exi, Eni, Hei & Index & Exi, Eni, Hei \\
\hline$A_{11}$ & $86.000,0.000,0.000$ & $A_{43}$ & $85.533,1.961,0.650$ & $B_{31}$ & $75.000,0.000,0.000$ & $C_{14}$ & $91.400,1.604,0.175$ \\
$A_{12}$ & $89.600,2.206,0.718$ & $A_{44}$ & $91.200,1.437,0.682$ & $B_{32}$ & $13.000,0.000,0.000$ & $C_{21}$ & $90.400,1.504,0.372$ \\
$A_{21}$ & $91.000,1.337,0.270$ & $B_{11}$ & $87.867,2.518,0.265$ & $B_{33}$ & $57.000,2.172,0.071$ & $C_{22}$ & $88.733,2.150,0.520$ \\
$A_{22}$ & $80.667,2.618,0.688$ & $B_{12}$ & $64.267,3.075,0.202$ & $B_{41}$ & $90.000,0.000,0.000$ & $C_{23}$ & $92.933,1.270,0.410$ \\
$A_{23}$ & $70.467,1.794,0.722$ & $B_{13}$ & $98,000,0.000,0.000$ & $B_{42}$ & $90.000,0.000,0.000$ & $C_{24}$ & $90.933,1.415,0.279$ \\
$A_{31}$ & $89.267,1.526,0.346$ & $B_{21}$ & $90.000,0.000,0.000$ & $B_{43}$ & $50.000,0.000,0.000$ & $C_{31}$ & $80.133,1.705,0.275$ \\
$A_{32}$ & $89.267,1.860,0.420$ & $B_{22}$ & $69.000,0.000,0.000$ & $C_{11}$ & $88.467,2.796,0.916$ & $C_{32}$ & $69.333,1.838,0.045$ \\
$A_{41}$ & $90.333,1.281,0.558$ & $B_{23}$ & $92.000,0.000,0.000$ & $C_{12}$ & $90.533,1.883,1.137$ & $C_{41}$ & $78.933,2.429,0.510$ \\
$A_{42}$ & $93.067,1.604,0.280$ & $B_{24}$ & $98.000,0.000,0.000$ & $C_{13}$ & $90.933,2.262,0.578$ & $C_{42}$ & $82.000,0.000,0.000$ \\
\hline
\end{tabular}

Note: Table 6 is calculated from Equations (4.1) to (4.6) for the collected raw data.

Among them, some entropy Eni and super-entropy Hei of the indicator cloud are zero. As the indicator is a quantitative indicator, its data are obtained based on the field survey of the general contractor, and the quantitative data are the same, so the entropy and super-entropy of some indicators are zero. By combining the comprehensive weight WI of the indicator system obtained above with the current indicator clouds, $\mathrm{Ex}=82.782, \mathrm{En}=7.216, \mathrm{He}=0.296$ are calculated through equations 4.2.1, 4.2.2 and 4.2.3. Therefore, the current comprehensive evaluation cloud of the project is $(82.782,7.216,0.296)$. The cloud map was drawn by MATLAB2018a, as shown in Figure 2 and Figure 3.

Figure 2 shows the cloud map of green construction evaluation standard, Figure 3 shows the membership degree of evaluation comprehensive cloud map and standard cloud map. As shown in Figure 3, the comprehensive cloud map of the current project belongs to the grade of "good".

\subsection{Calculating Membership Degree}

The membership degree of the 5 evaluation grades of the comprehensive evaluation cloud $(82.782,7.216,0.296)$ calculated in 5.2 and the evaluation standard cloud is shown in the following table through the four steps in 4.3: This process is realized by software MATLAB2018a, with $\mathrm{n}=3000$ (Table 7).

It can be concluded from the table that the membership degree of green construction grade and standard evaluation cloud grade 4 of the current project is the largest, 0.5007 . According to the validity principle of the maximum membership degree, the current membership degree greater than 0.5 is effective (Chen \& Sun, 2001). Therefore, through the comprehensive cloud map and the principle of maximum membership, the current green construction grade is determined as "good". Finally, the evaluation results are fed back to the general contractor, and the staff of the contractor generally think that the results are consistent with the current green construction effect, which proves the effectiveness and applicability of the evaluation model. 
Table 7. Comprehensive cloud membership degree.

\begin{tabular}{cccccc}
\hline Standard cloud & 1 & 2 & 3 & 4 & 5 \\
\hline Membership & 0.1311 & 0.054 & 0.32289 & 0.5007 & 0.1729 \\
\hline
\end{tabular}

Note: The data in Table 7 are calculated by MATLAB software.

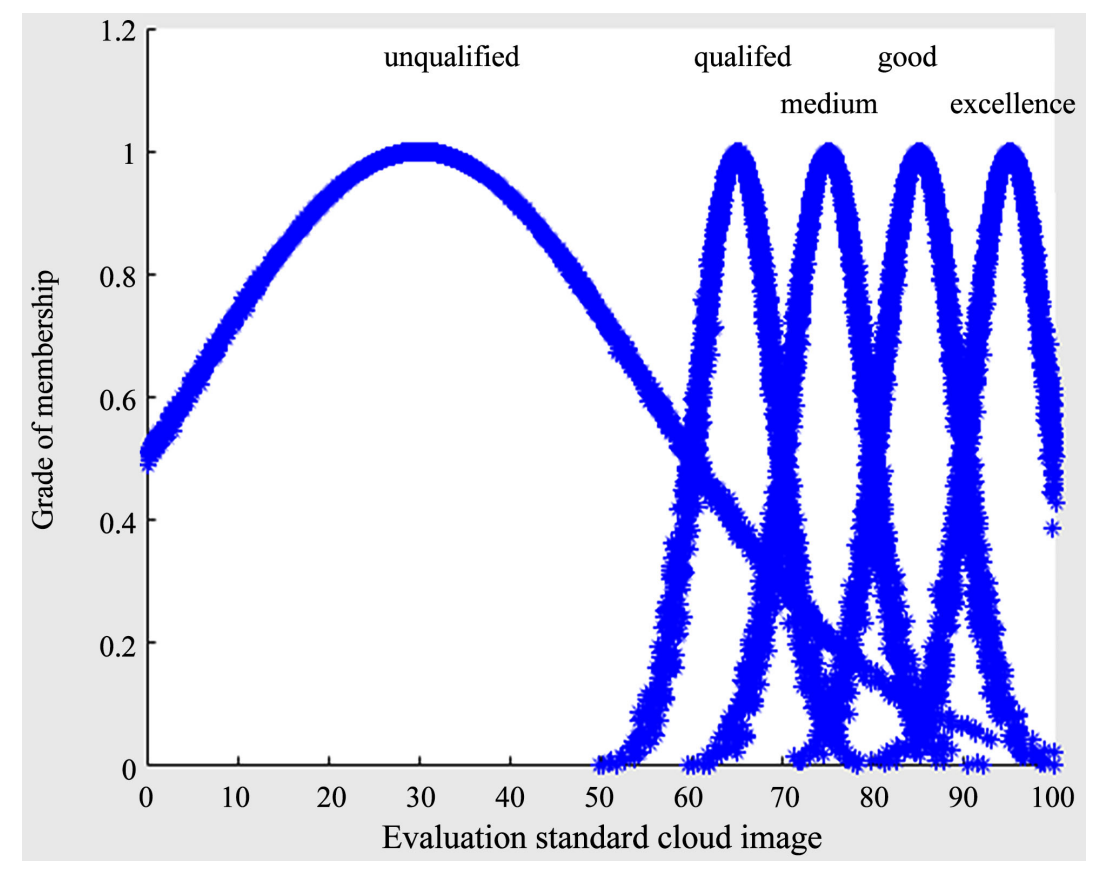

Figure 2. Evaluation standard cloud image. Note: Figure 2 is drawn by MATLAB software.

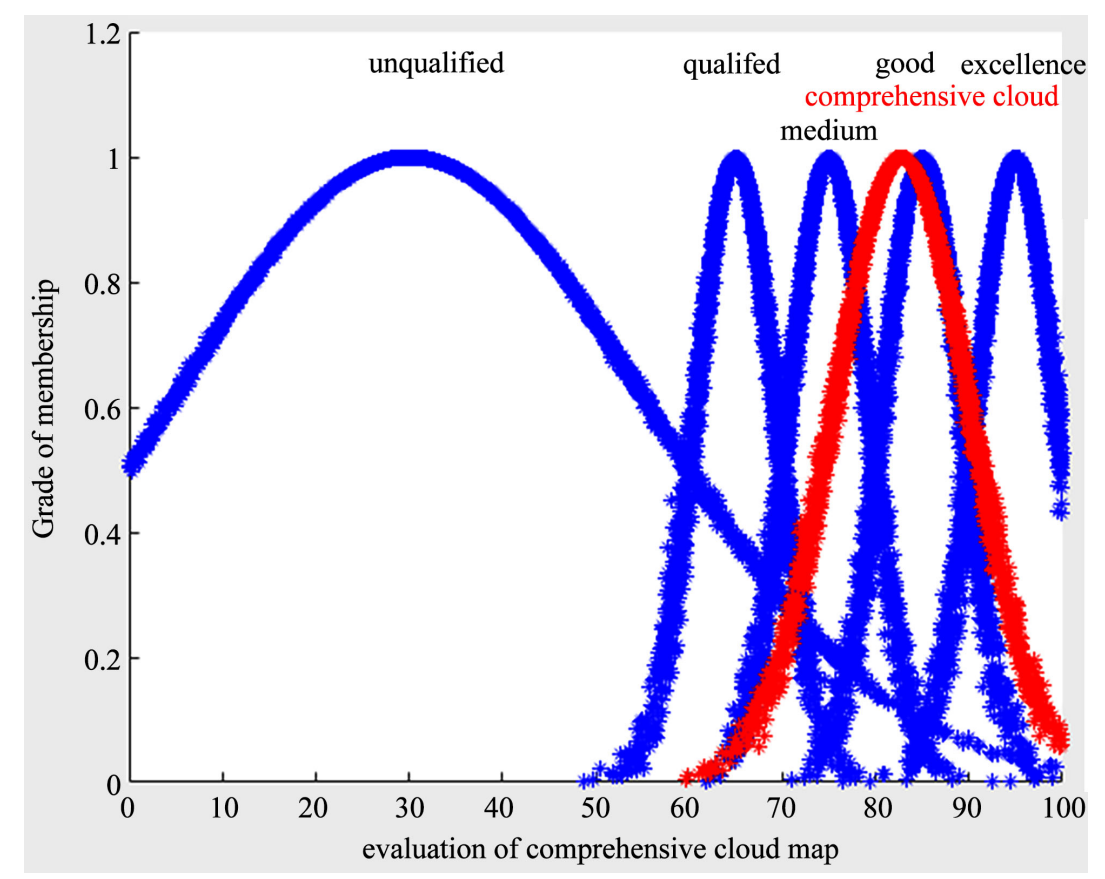

Figure 3. Evaluation of comprehensive cloud image. Note: Figure 3 is drawn by MATLAB software. 


\subsection{Analysis of Empirical Results}

It can be seen from the weight of the above table that the current construction units will be safe and will be the management of environmental protection is very important. It can be seen from the above table that the comprehensive score of safety and health and environmental protection of the current general contractor has basically reached the excellent grade, but the layout of fire protection facilities in safety and health is rated as good and needs to be improved. Fi2re is the key disaster in the process of high-rise building construction, and fire prevention facilities have an extremely important role in fire prevention and response to the occurrence of fire, so the installation and layout of fire prevention facilities should be strengthened. At the same time, it can be seen from the above table that energy saving and utilization is not very good in the current green construction, especially the saving of electric energy, which is the lowest score of the evaluation of green construction and should be continuously improved. Saving electricity not only saves social resources, but also reduces expenditure for the unit itself. Therefore, saving electricity should be taken as the focus of improvement at present, while improving the utilization efficiency of green energy. Finally, construction road, personnel change, utilization rate of water-saving equipment and waste disposal are the items with low evaluation scores, which should be strengthened and improved in the future green construction.

\section{Conclusion}

The evaluation index system of high-rise building is selected through literature research, and the evaluation standard is established based on relevant norms, and the weight of evaluation index is established by ahP-entropy weight method, which avoids the disadvantages and deviations of single weight method to a certain extent and makes the weight of evaluation index more objective and reasonable. Considering the fuzziness and randomness of indicators, cloud model is adopted as the evaluation model to solve the problems of fuzziness and randomness of indicators in the evaluation process. By drawing comprehensive cloud map and calculating the membership degree of comprehensive evaluation cloud and standard cloud, the evaluation results are more accurate. Finally, the practicability of the current evaluation model is verified by a specific case, and data support and guidance are provided for improving green construction measures for engineering examples.

At present, China is in the era of rapid development, so the analysis and research of relevant theories should also catch up with the pace of the rapid development of the construction industry. Therefore, the author suggests that the future research on green construction should be further analyzed from the following two perspectives:

1) Green construction index mechanism must be constantly updated and improved. The index system currently constructed by the author is actually at the basic level of discussion, and further research and analysis are needed on the 
specific refinement of various indexes in the future.

2) The evaluation means of green construction must be diversified. Green construction is a complex system engineering affected by many factors, so it is necessary to improve the evaluation means and tools to ensure a more detailed evaluation process and more accurate evaluation results.

\section{Funding}

Sichuan Science and technology plan project: Study on economic vulnerability and Countermeasures of green buildings in Sichuan (Project No.: 2020JDR0239)

\section{Conflicts of Interest}

The authors declare no conflicts of interest regarding the publication of this paper.

\section{References}

Chai, N. J., Bao, X., \& Wang, Q. (2017). Research on Evaluation Method of Railway Green Construction Project Based on Grey Clustering Evaluation Model. Engineering Research-Engineering in Interdisciplinary Perspective, 9, 300-306.

Chen, X. H. (2006). Green Construction Evaluation Based on Analytic Hierarchy Process. Construction Technology, No. 11, 85-89.

Chen, Y., \& Sun, C. (2001). The Validity of Maximum Subordination Principle in Fuzzy Comprehensive Evaluation Method. Journal of Chongqing Normal University (Natural Science Edition), No. 1, 45-47.

Gao, L., Wang, M., Huang, S., \& Sun, D. (2017). Research on Evaluation Model of Subway Green Civilization Construction Grade Based on Fuzzy Comprehensive Evaluation Method. Construction technology, 46, 96-99.

Gao, X. (2009). Research on Public Project Performance Evaluation System and Performance Realization Mechanism. Tianjin University.

Guo, R., Shen, H., \& Yang, M. (2021). Evaluation of Land Ecosystem Health Based on Improved PSR Model in Changsha-Zhuzhou-Xiangtan Region. Environmental Monitoring Management and Technology, 33, 29-34.

Hu, F. (2012). Research on Performance Evaluation of Large-Scale Public Engineering Projects. Hunan University.

Li, J., \& Liu, S. (2021). Evaluation of Regional Green Innovation Development Level in China Based on PSR Model. Industrial Technology Economics, 40, 82-88.

Li, L. (2012). Research on 6 E Comprehensive Evaluation System of Building Material Greenness. Dalian University of Technology.

Li, Y. P., Li, R., \& Wei, Y. (2018a). Green Construction Evaluation Based on BP Artificial Neural Network. Journal of Wuhan University of Technology, 40, 76-81.

Li, Y. P., Liu, M., \& Wang, F. (2018b). Research on Sponge City Project Performance Evaluation Based on Cloud Model. Chinese Landscape Architecture, 34, 45-49.

Shi, Z. W., \& Hua, S. X. (2019). Study on Evaluation System of Highway Green Construction in Seasonal Freezing Region Based on Grey Clustering Method. Highway Engineering, 44, 73-79.

Wang, A. L. (2014). Green Construction Evaluation of Building Engineering Based on 
Improved Vague Similarity Summary Method. Science and Technology Management Research, 34, 100-103+120.

Wang, Q. K., Nian, C., \& Deng, Q. (2020). Evaluation Method of Prefabricated Building Construction Greenness Based on Cloud Matter-Element Theory. Construction Economy, 41, 84-89.

Xie, S. J. (2018). Construction Evaluation of Water Conservancy and Hydropower Projects Based on Green Construction Evaluation Index System. Heilongjiang Water Resources Science and Technology, 46, 219-223.

Xue, L., \& Zhao, S. (2021). Evaluation of Urban Rail Transit Operation Level Based on PSR Model and Game Combination Weighting. Railway Transportation and Economy, 43, 123-129.

Yang, T., Yu, C., Fan, M., \& Wang, X. (2008). Evaluation of Green Construction Based on Grey Clustering Method. Sichuan Building Research, 34, 223-227. 